\title{
EFFECT OF SERVICE TEMPERATURE CONDITIONS ON THE ELECTROMOTIVE FORCE OF UNSATURATED PORTABLE STANDARD CELLS
}

\author{
By J. H. Park
}

\section{ABSTRACT}

The effect of external temperature disturbances such as might occur in practice on the electromotive force (emf) of unsaturated portable standard cells of the models in general use as secondary standards, was investigated. The experiments included unequal heating of different parts of the cell and sudden changes of temperature. Temporary changes in cell emf, caused by these disturbances, in some cases as large as $1.8 \mathrm{mv}$ (nearly 0.2 of 1 per cent), were measured and the results are shown by curves. During all tests the cell elements were left in the cases furnished with them. Methods of protecting the cells from external temperature disturbances were tried and their effectiveness is shown.

\section{CONTENTS}

I. Introduction and purpose- Page

II. Effect of temperature inequality of the limbs.

III. Hysteresis effects.

IV. Summary 98

\section{INTRODUCTION AND PURPOSE}

Nearly all persons who regularly use the unsaturated portable cadmium cell (also called the Weston cell) as a standard of emf have been cautioned (1) to keep all parts of their cells at the same temperature, (2) to avoid sudden changes in the temperature of the cell, (3) not to submit the cells to temperatures below $4^{\circ} \mathrm{C}$. or above $40^{\circ} \mathrm{C}$., and (4) not to draw more than 0.0001 ampere from a cell. Changes in the emf of a cell due to deviations from these rules have been investigated and briefly summarized in a very comprehensive discussion of standard cells by Eppley. ${ }^{1}$ However, results were not given for the cell elements in their cases, as they are generally used, and temperature effects depend upon the thermal insulation which envelops the cell element as well as the external temperature conditions.

The purpose of this investigation was to determine the effect on the emf of an unsaturated cell (1) when the limbs of the cell are at unequal temperatures as a result of conditions simulating those which might exist in practice, and (2) when the cell is subjected to a sudden change in temperature. All experiments were performed on the models of cells in general use and the glass elements of these cells

\footnotetext{
1 Eppley, Trans. of the A. I. E. E., vol. 50, No. 4, p. 1293, December, 1931.
} 
were thermally insulated by the cases furnished with them. In some experiments additional thermal shielding was used to determine its effectiveness in protecting the cells from temperature disturbances.

The general nature of the effects here described has been known for a long time, but it is believed their magnitude has often been underestimated. The present paper is intended therefore to show these magnitudes and to direct attention to the importance of taking suitable precautions in order to obtain the precision of which standard cells are capable. Further studies are being made of the causes underlying these effects.

\section{EFFECT OF TEMPERATURE INEQUALITY OF THE LIMBS}

The temperature coefficients of unsaturated portable cells are negligible $^{2}$ for practical purposes. However, the over-all temperature coefficient is the algebraic sum of the coefficients of the two limbs of the cell. The temperature coefficient of each limb taken separately ${ }^{3}$ is quite large, but the two are opposite in sign. Thus, when the temperatures of the two limbs of a cell are changed by an equal amount the resulting change in the final steady value of the emf of the cell will usually be very small, but when the temperatures of the two limbs are changed by unequal amounts the resulting change in the emf of the cell will be relatively large, its magnitude depending upon the amount of temperature inequality. Inequalities of temperature are liable to occur in practice (1) if the cell is placed near a hot radiator, a resistor carrying current, a lighted lamp, or a cold wall; (2) if the cell is placed where the sun's rays will strike it; (3) if the cell is held in the bare hand; or (4) if the cell is placed where hot or cold air will strike it (such as in the draft from a register or cold-air duct or near an open window in the winter time). The above are the more obvious causes of irregular heating of cells, but must not be considered to be every possibility.

Several models of cells were subjected to most of the temperature conditions just mentioned, the procedure being as follows: The emf of the cell under test was first noted for a sufficient time to make sure it was steady. Then the cell was subjected to the temperature condition and its emf was measured every 10 minutes until it had reached a steady value. Next, the source of heat was removed and the emf was again measured every 10 minutes until it was steady and very close to its original value. In one experiment the temperature difference between limbs was also measured by placing a thermocouple inside the cell case with each junction in contact with one of the limbs.

The emf of the cell under test was found by comparing it with the emf of a reference cell, the small difference being measured by means of a simple potentiometer of the Lindeck-Rothe type. An unsaturated cell in good condition, placed in an additional container (shown in fig. 1) for protection against temperature inequality, was used as the reference cell.

Three models (designated here as A, B, and C) of unsaturated portable standard cells which are in general use as secondary standards of emf, were tested. Cells of models A and C were in bakelite cases, 2 Weston, The Electrician, vol. 30, p. 741, 1892. Vosburgh and Eppley, J. Opt. Soc. of Am., vol. 9, p.
72,1924 .

F. E. Smith, Phll. Mag., vol. 19, p. 272, 1910. 
and cells of model B were in metal cases. Several cells of each model were tested, but since all cells of the same model gave practically the same performance, data are given here for only one cell of each model.

The results of the experiments to determine the effect of temperature inequalities are shown by the curves in Figures 2 to 6 . Curves in Figure 2 show the results on a standard cell of model $\mathrm{A}$, when it was placed near a 16-inch slide rheostat dissipating 288 watts. The inserted diagram shows the position of the cell with respect to the rheostat. Curves $A$ and $B$ show the effect on emf when the cell was placed 10 inches from the heated rheostat. When the positive limb is nearer to the rheostat (curve $A$ ), its temperature is higher
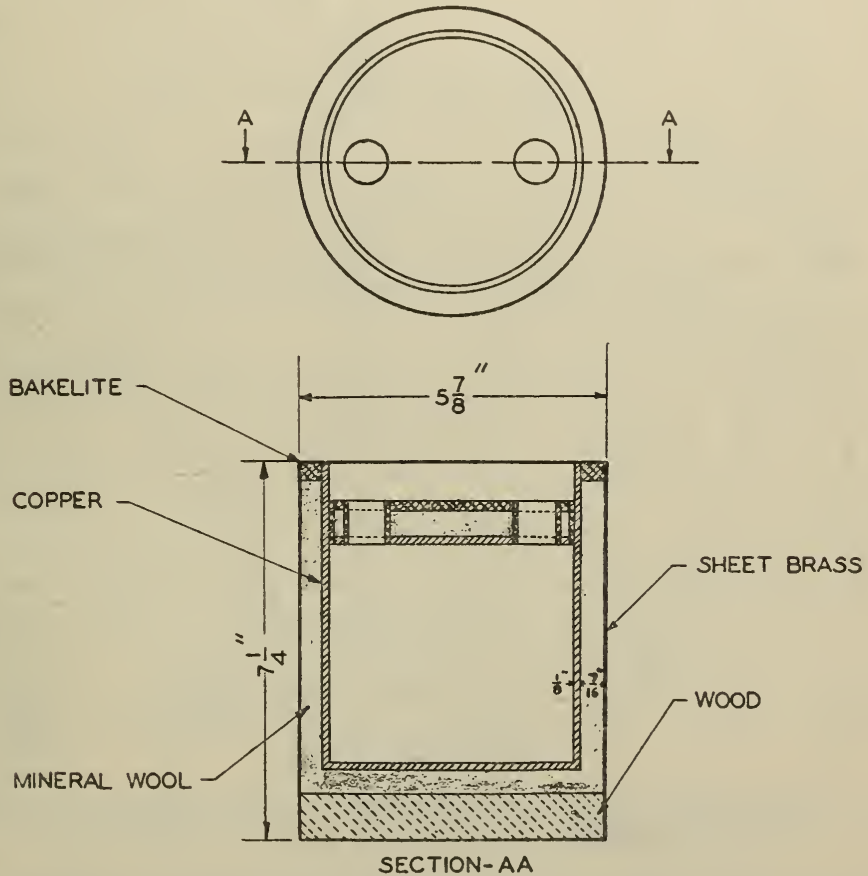

FIGURE 1.- Standard cell container for protection against temperature inequality

Designed at the Bureau of Standards in 1927.

than that of the negative limb, and the cell emf increases. When the negative limb is nearer to the rheostat (curve $B$ ), its temperature is higher than that of the positive limb, and the cell emf decreases. These curves illustrate the fact that the temperature coefficients of the two limbs of the cell taken separately have the opposite effect on the cell emf, also that the effects are about the same per degree difference in temperature. In curve $A$ the emf of the cell does not return to its normal value until about 36 hours after removing the source of heat; this and other slight irregularities which may occur in the cooling part of the curves are due to the hysteresis effect which will be taken up later. Curve $E$ shows the temperature difference between the limbs of the cell under the same heating conditions as for curves $A$ and $B$. As seen from curves $A, B$, and $E$, a temperature difference 
of $2.7^{\circ} \mathrm{C}$. between the limbs of the cell causes a change in emf of about $1 \mathrm{mv}$.

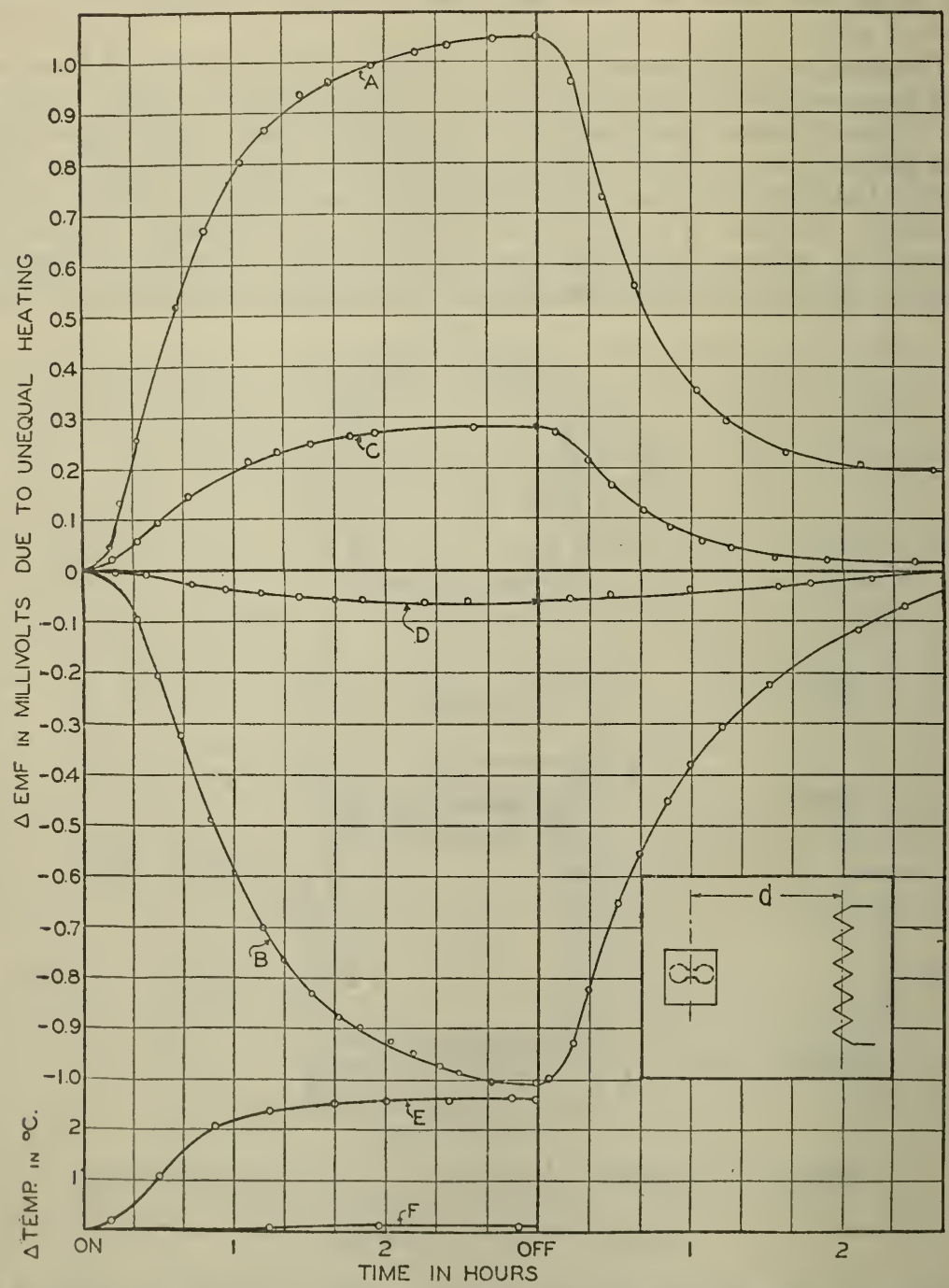

Figure 2.-Temperature inequality effects on standard cell model $A$, caused by heat from a 16-inch slide rheostat dissipating 288 watts

Curve $A$, effect on emf when $d=10$ inches, positive limb nearer to rheostat. Curve $B$, effect on em/ when $d=10$ inches, negative limb nearer to rheostat. Curve $C$, effect on emf when $d=20$ inches, positive limb nearer to rheostat. Curve $D$, same as curve $B$ with cell in special container. Curve $E$, temperature difference between limbs when $d=10$ inches. Curve $F$, same as curve $E$ with cell in special container

Curve $C$ (fig. 2) shows the effect on the emf when the cell was placed 20 inches from the heated rheostat. By comparing this curve with curve $A$, it is seen that the change in emf due to unequal heating happens to vary approximately inversely as the square of the distance from the rheostat. 
Curves $D$ and $F$ (fig. 2) show the results when the cell was placed in a protecting container (shown in fig. 1) and submitted to the same heating conditions as for curves $A, B$, and $E$. As seen from curve $F$, a container of this sort practically eliminates temperature inequality in the cells. The change in the emf of the cell, shown by curve $D$, is partially due to the fact that the temperatures of both limbs of the cell were increased about $5^{\circ} \mathrm{C}$. due to the radiation of heat from the rheostat.

The curves in Figure 3 show the results obtained when the experiments just described were repeated, using a standard cell of model B.

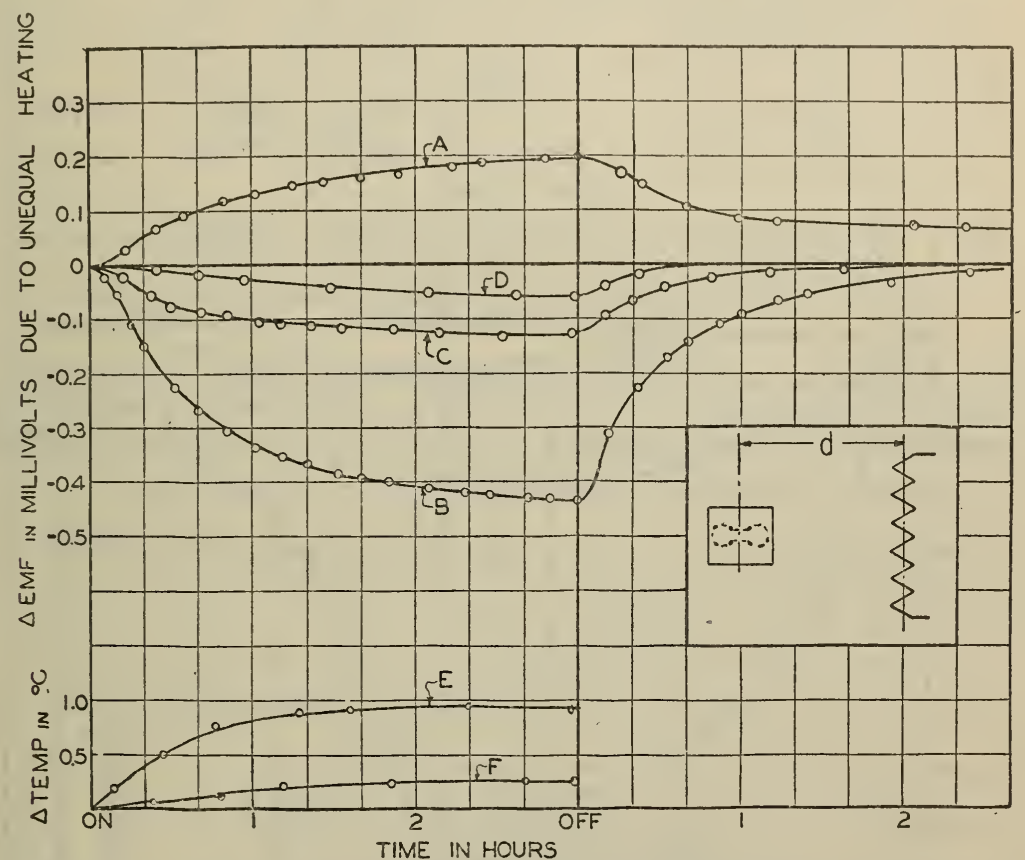

FIgURE 3.-Temperature inequality effects on standard cell model $B$, caused by heat from a 16-inch slide rheostat dissipating 288 watts

Curve $A$, effect on emf when $d=10$ inches, positive limb nearer to rheostat. Curve $B$, effect on emf when $d=10$ inches, negative limb nearer to rheostat. Curve $C$, effect on emf when $d=20$ inches, negative limb nearer to rheostat. Curve $D$, same as curve $B$, with cell in special container. Curve $E$, temperature difference between limbs when $d=10$ inches. Curve $F$, same as curve $E$, with cell in special container

The metal case of this model tends to equalize the temperatures of the two limbs, and the curves show that the same heating condition causes a much smaller temperature difference and therefore a much smaller change in emf than for a cell in a bakelite case. The difference in maximum values between curves $A$ and $B$ may have been due to a difference in the cotton and wood thermal insulation between the metal case and the limbs of the cell.

The curves in Figure 4 are the results of similar experiments performed on a standard cell of model $C$. The case of this cell was too large to fit into the container used for the previous cells in obtaining data for curves $D$ and $F$. However, there was sufficient space inside the bakelite case to allow the insertion of a copper lining one-sixteenthinch thick. The results indicate this method of equalizing cell tem- 
perature to be as effective for a cell of this model as the use of a special container was for cells of models $A$ and $B$.

The curves in Figure 5 show the change in the emf of the cell due to the hert of the hand, held continuously on one side of the cell case for over two hours. The curves in Figure 6 show the change in emf

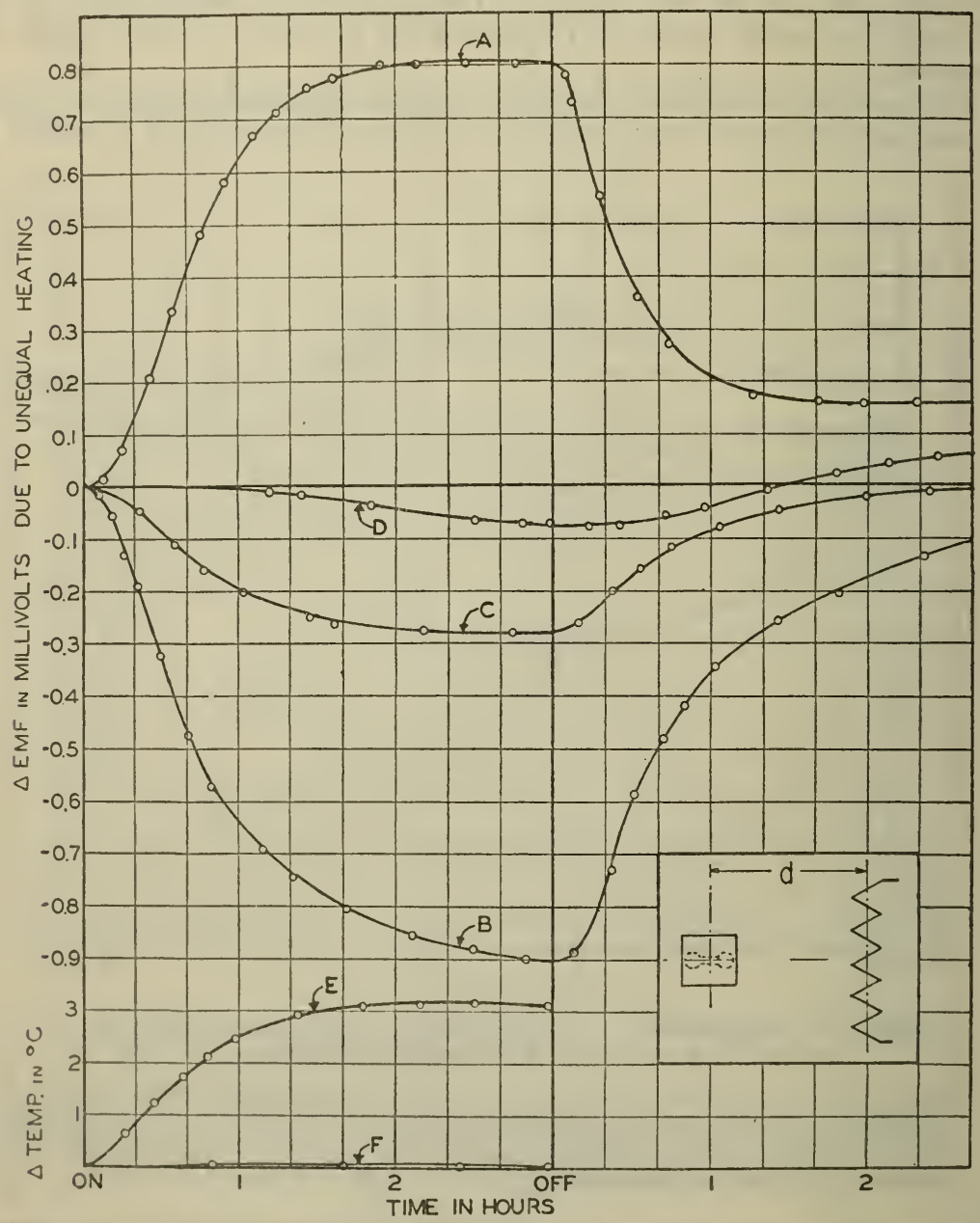

FIGURE 4.-Temperature inequality effects on standard cell model $C$, caused by heat from a 16-inch slide rheostat dissipating 288 watts

Curve $A$, effect on emf when $d=10$ inches, positive limb nearer to rheostat. Curve $B$, effect on $\mathrm{em}$ ? when $d=10$ inches, negative limb nearer to rheostat. Curve $C$, effect on emf when $d=20$ inches, negative limb nearer to rheostat. Curve $D$, same as curve $A$, with cell case copper lined. Curve $E$, temperature difference between limbs when $d=10$ inches. Curve $F$, same as curve $E$, with cell case copper lined

due to the heat of the sun's rays, shining continuously on one side of the cell case for over two hours. For both of the above conditions the cell and the source of heat were arranged to give the maximum opportunity for temperature inequality of the two limbs of the cell. Curves are shown for the three models of cells in their usual cases and the differences between the behavior of these cells under the same conditions are largely due to the differences of their cases. 
Change in the emf of a cell due to unequal heating caused by radiation from a 40-watt lamp placed 1 foot from the cell was found to be under $50 \mu v$.

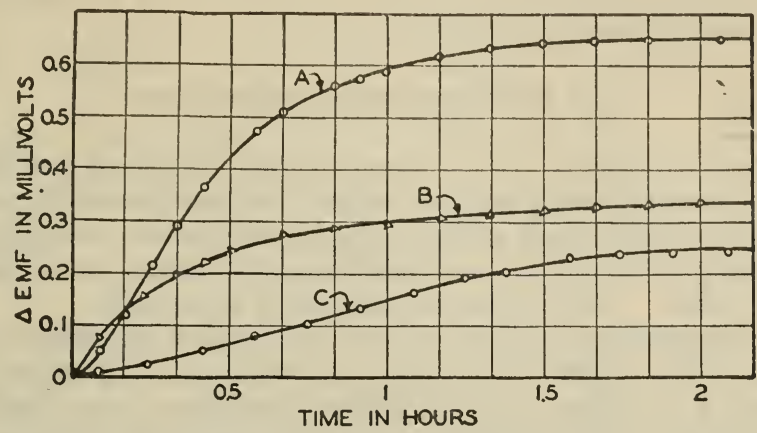

FIGURE 5.-Change in standard cell emf due to the heat of the hand, held continuously on one side of the cell case

Curve $A$, standard cell model A. Curve $B$, standard cell model $\mathrm{B}$. Curve $C$, standard cell model C

The results of the above experiments should not be applied quantitatively as a correction to other cells of the same model under like temperature disburbances, because variables such as room tempera-

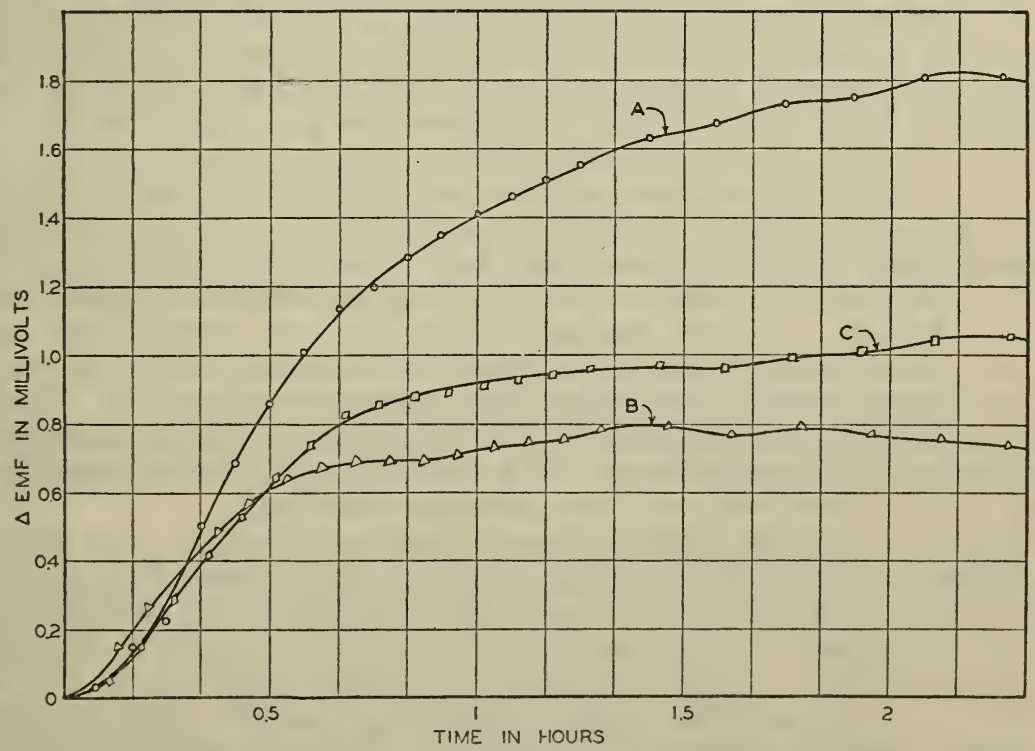

FIGURE 6.-Change in standard cell emf due to exposure of one side of cell case to sunlight

Curve $A$, standard cell model A. Curve $B$, standard cell model B. Curve $C$, standard cell model C

ture or condition of the cell may cause cells of the same model to have different changes in emf for the same external temperature disturbance. However, the results shown may be used as a guide for the user to determine whether protection against temperature inequality is 
needed for the accuracy required. The methods mentioned here for protection against temperature inequality are probably sufficient for all practical work. However, where high precision ( 0.01 of 1 per cent or better) is required, more effective methods of protection against temperature disturbances should be used.

\section{HYSTERESIS EFFECTS}

When the temperature of an unsaturated standard cell is changed, all parts of the cell being held at equal temperatures throughout the change, the emf of the cell will change rapidly until a steady temperature is reached. Then the emf will slowly return to approximately its original value. This effect is known as hysteresis.

Several different theories have been advanced to explain the causes of this hysteresis effect. However, it was not the purpose of this investigation to explain any of these theories or to obtain data in support of them. It is well known that hysteresis is present in most cells to a greater or less extent, and that the effect is more pronounced with a declining temperature than with a rising temperature. The purpose of the experiments to be described was to find within what limits the hysteresis error lies for the unsaturated portable cells which are in general use, also to determine what means might be employed to reduce these errors.

Six cells, of various models and ages, taken from a group in regular laboratory use, were tested for hysteresis. In order to duplicate as nearly as possible the conditions in practice, the cells in their usual cases were placed in a temperature-controlled air bath. ${ }^{4}$ The air was circulated by a blower and its temperature was held constant to within $\pm 0.1^{\circ} \mathrm{C}$. by a thermostat which operated a heater in the air stream. The bath temperature was first held at $23^{\circ} \mathrm{C}$. until the cell emf's became constant. Then it was changed to $27^{\circ} \mathrm{C}$. (time required being about two hours) and held there, measurements of the emf of all cells being made at frequent intervals until the equilibrium values for $27^{\circ} \mathrm{C}$. were reached. Next the air temperature was changed back to $23^{\circ} \mathrm{C}$. (in about two hours) and held there, measurements again being made until equilibrium was reached. These measurements were made in the same way as in the temperatureinequality experiments except that a saturated cell ${ }^{5}$ in a temperaturecontrolled oil bath was used as a reference standard.

The results of the hysteresis experiments are shown by the curves in Figure 7. Time after starting to change the ambient temperature was plotted as abscissas and change in the emf of the cell as ordinates. Curve $A$ shows the effect on the emf of Cell II (cell with the least hysteresis) when the temperature was raised from $23^{\circ}$ to $27^{\circ} \mathrm{C}$. Curve $B$ shows the effect on the emf of the same cell when the temperature was lowered from $27^{\circ}$ to $23^{\circ} \mathrm{C}$. Curves $C$ and $D$ show the effect on the emf of Cell IV (cell with the most hysteresis) under the same temperature changes as for Cell II. Hysteresis curves of Cells I, III, V, and VI lie between those of Cells II and IV, but are not shown. The results of measurements on these six cells did not show any correlation between cell emf, model of cell, or age of cell and hysteresis effect. One of the newest cells with a high emf showed

- This temperature-controlled cabinet was designed by A. E. Peterson.

The eml of this cell was checked by Miss M. L. Howard at least once a week against the average of the 20 colls which constitute the bureau's reference standard of emf. 
much greater hysteresis than one of the oldest cells with a low emf. Therefore, it is very difficult, if not impossible, at the present time to predict just what the hysteresis error of any given cell will be. However, from the curves in Figure 7, an approximation may be had as to within what limits the hysteresis error of any unsaturated portable cell in good condition ${ }^{6}$ might fall. Eppley ${ }^{7}$ found that when an unsaturated cell was suddenly cooled from $30^{\circ}$ to $25^{\circ} \mathrm{C}$. the average hysteresis error was from 0.02 to 0.027 per cent. This average error lies within the limit shown here.

A method of protecting cells from hysteresis errors was applied to Cell IV, which was chosen because of its large hysteresis. It was placed inside a container (such as shown in fig. 1) and this container

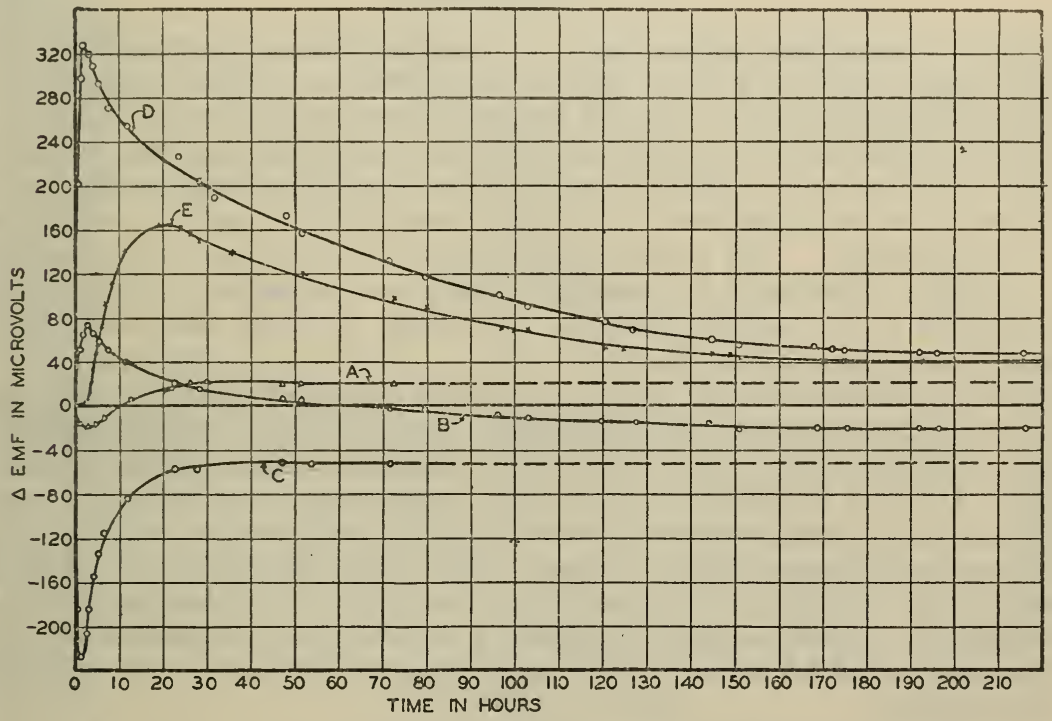

FIGURE 7.-Hysteresis effect on portable unsaturated standard cells

Curve $A$, effect on emf of Cell II, when temperature was changed from $23^{\circ}$ to $27^{\circ} \mathrm{C}$. Curve $B$, effect on emf. of Cell II, when temperature was changed from $27^{\circ}$ to $23^{\circ} \mathrm{C}$. Curve $C$, effect on emf of Cell IV, when temperature was changed from $23^{\circ}$ to $27^{\circ} \mathrm{C}$. Curve $D$, effect on emf of Cell IV, when temperature was changed from $27^{\circ}$ to $23^{\circ} \mathrm{C}$. Curve $E$, same as curve $D$ with cell in insulated box

was placed in a wooden box which was sufficiently large to leave about 3 inches of space between the container and the box on all sides, mineral wool being loosely packed in this space. The cell, thus thermally insulated, was placed in the constant-temperature cabinet, set for $27^{\circ} \mathrm{C}$. and maintained at this temperature until the emf of the cell became steady. Then the air temperature was lowered to $23^{\circ} \mathrm{C}$. and held there, readings of the emf being taken regularly until it again became constant. The results of this experiment are shown by curve $E$ in Figure 7. By comparing this curve with curve $D$ it may be seen that thermally insulating the cell decreases the hysteresis effect by about 50 per cent in the case of a sustained temperature change. However, under ordinary laboratory conditions, where the average temperature over a period of 24 hours does not change much from day

- Cells which are not in good condition may show much greater hysteresis errors.

I See reference 1, p. 1299. 
to day, thermally insulating a cell would be of great benefit in smoothing out the hour-to-hour temperature changes, thus greatly reducing the hysteresis error.

In instances where large sustained temperature changes occur, the only means of eliminating hysteresis errors is to keep the cell in a container whose temperature can be thermostatically controlled. However, as noted from curves $A$ and $B$ (fig. 7 ) some cells have very low hysteresis errors. In cases where high accuracy is required and the necessary means for eliminating hysteresis are not feasible, it would be advisable to use a particular cell whose hysteresis has been observed and found to be small.

\section{SUMMARY}

Temperature inequality between the two limbs of a standard cell, which may occur (1) when the cell is placed near a heat source, such as a hot radiator or a rheostat carrying current; (2) when the cell is placed where the sun's rays will strike it; (3) when the cell is placed where cold air will strike it; or (4) when the cell is held in the hand, caused an error in the emf of the cell of about $300 \mu \mathrm{v}$ per ${ }^{\circ} \mathrm{C}$. difference in temperature. The temperature inequality between limbs can be practically eliminated by placing the cell in a container such as shown in Figure 1, or, where possible, by lining the cell case with sheet copper one-sixteenth inch thick.

The hysteresis error, which occurs in portable unsaturated cells when their temperature is changed, varies widely among different cells, and the only way to determine this error for a given cell is to check its emf immediately after its temperature has been changed. Errors due to hysteresis may be reduced by sufficiently insulating the cell against changes in temperature; but the only way to eliminate these errors is to keep the cell in a box whose temperature is thermostatically controlled. Under normal laboratory conditions precautions against hysteresis need be taken only if accuracies of 0.03 per cent or better are required.

Washington, October 12, 1932. 